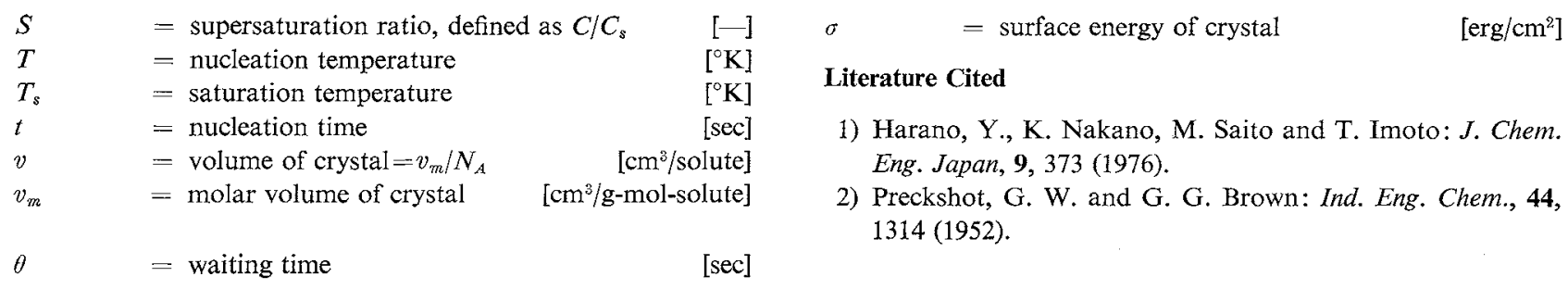

\title{
A NOTE ON THERMAL EFFICIENCY OF CHEMICAL HEAT PUMP
}

\author{
Hideo KAMEYAMA, Sigetaka FUJII and Tohru KAWAHARA \\ Department of Chemical Engineering, University of Tokyo, Tokyo 113 \\ KUNIO YOSHIDA \\ Engineering Research Institute, University of Tokyo, Tokyo 113
}

\section{Introduction}

A concept "chemical heat pump" was proposed" for recovering low-level thermal energy, and as an example of its system " $\Delta-1$ " process was described. In the preceding paper we showed that the efficiency defined as a ratio of energy recovered to energy required for the operation will be $27 \%$ for the " $\Delta-1$ " process and, therefore, that the chemical heat pump will be potentially competitive with other recovery methods. However, since an aim of the chemical heat pump is to pump up thermal energy from lower to higher temperatures, a comparison of efficiency with the conventional heat pump system should rather be made in the light of capability for pumping up energy.

\section{Thermal Efficiency}

The function of the chemical heat pump (ChHP) is considered to be a combined system of the heat engine and the heat pump. Therefore, systems illustrated by Fig. 1(a) and (b) are compared. In case all chemical reactions proceed ideally, no external work would be required in the ChHP. But, due to irreversibility being involved in practical operations, some amount of external work is needed. Thus, a heat engine is considered to supply the work, as shown in Fig. 1(a). The practical efficiency of heat engine in both systems (a) and (b) has the same value, defined as $\eta_{Q W}$.

Let us define the ratio of the heat output at temperature $T_{1}$ to the heat input at temperature $T_{2}\left(T_{1}>T_{2}\right)$ as

Received October 3,1977. Correspondence concerning this article should be addressed to K. Yoshida. S. Fujii is now with Mitsui ToatsuU Chemicals, Inc., Osaka 592. the thermal efficiency. Then the thermal efficiency of ChHP system by Fig. 1 (a) is given by

$$
\begin{aligned}
\eta_{C} & =Q_{C 1} /\left(Q_{C 2}+Q_{C 2}^{\prime}\right)=1 /\left\{Q_{C^{2}} / Q_{C 1}+W_{C} /\left(Q_{C 1} \cdot \eta_{Q W}\right)\right\} \\
& =1 /\left\{1 / \eta_{Q C}+1 /\left(\eta_{W C} \cdot \eta_{Q W}\right)\right\}
\end{aligned}
$$

where

and

$$
\left.\begin{array}{l}
\eta_{Q C}=Q_{C 1} / Q_{C 2} \\
\eta_{W C}=Q_{C 1} / W_{C}
\end{array}\right\}
$$

These values $\eta_{Q C}$ and $\eta_{W C}$ represent the efficiencies of performance with respect to heat and work, respectively. The former is calculated from characteristics of reactions forming the ChHP, i.e., 0.61 for the " $\Delta-1$ " process, while the latter is obtained from the results of actual operation.

On the other hand, the thermal efficiency of the com-

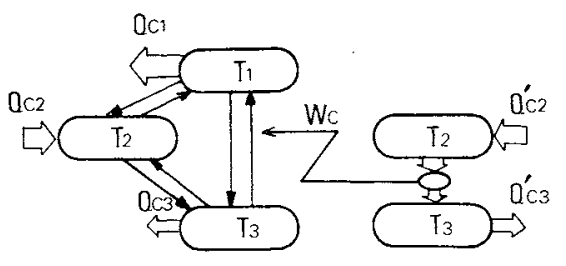

(a) Chemical heat pump

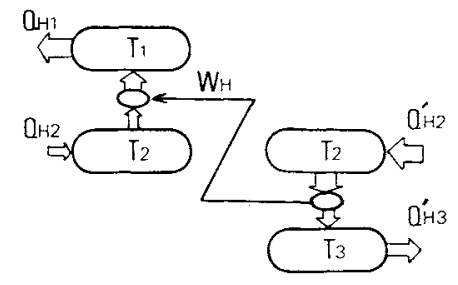

(b) Conventional process combining heat pump and heat engine

Fig. 1 Comparison of two systems 


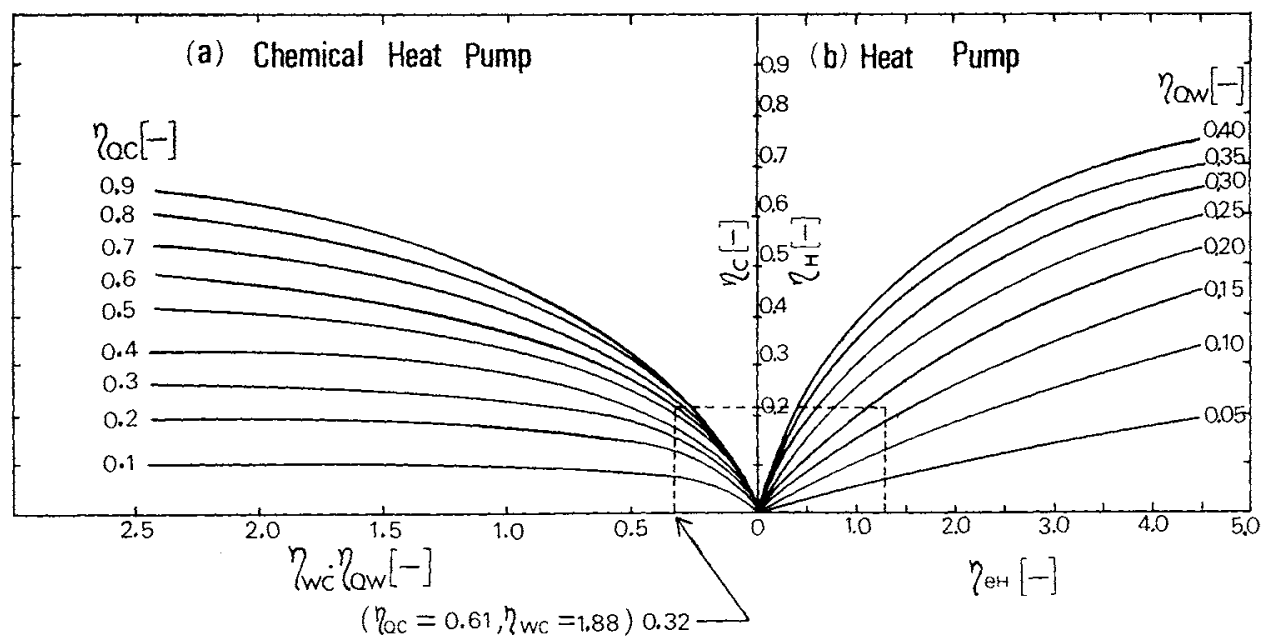

(a) Chemical heat pump system

(b) Conventional process combining heat pump and heat engine

Fig. 2 Efficiencies of two systems

bined system shown in Fig. 1 (b) is given by

$$
\eta_{H}=Q_{H 1} /\left(Q_{H 2}+Q_{H 2}^{\prime}\right) \leqq 1 /\left\{1-1 / \eta_{e H}+1 /\left(\eta_{e H} \cdot \eta_{Q W}\right)\right\}
$$

where the equality sign holds only for the reversible case and the value $\eta_{e H}$ represents the practical efficiency of heat pump. The maximum value of $\eta_{H}$ is obtained when the equality sign holds in Eq. (3). Thus, from Eqs. (1) and (3), both $\eta_{C}$ and the maximum $\eta_{H}$ are plotted in relation to several parameters, as shown in Fig. 2 (a) and (b).

\section{Results and Discussion}

Concerning the recovery of low-level thermal energy exhausted from industrial processes, the representative conditions of temperature for $T_{1}, T_{2}$ and $T_{3}$ are assumed to be $500^{\circ}, 200^{\circ}$ and $20^{\circ} \mathrm{C}$, respectively. The Freon-turbine is the only heat engine which is applicable today to heat recovery at low temperature. From published performance data on the Freonturbine $^{3)} \eta_{Q W}$ is 0.17 . Also, from the data on the heat pump ${ }^{22} \eta_{e r I}$ is given to be 1.3. Therefore, the thermal efficiency of the combined system becomes 0.21 . On the other hand, the value $\eta_{Q C}$ for ChHP is 0.61 when the " $\Delta-1$ " is considered to be representative of ChHP. Thus, the value of $\eta_{W C} \cdot \eta_{Q W}$, which is required to equalize $\eta_{C}$ to $\eta_{H}$, is 0.32 . The minimum requirement for $\eta_{W C}$, therefore, becomes 1.88 for the
" $4-1$ " process, as shown by a dotted line in Fig. 2 . This value is the process development target for the ChHP process.

\section{Conclusion}

Thermal efficiency of the chemical heat pump system was defined in the light of the capability for pumping up energy and, further, of comparison with that of the conventional heat pump system. The minimum requirement of the ChHP which must be satisfied to exceed the conventional heat pump system was given.

\section{Nomenclature}

$Q_{C}, Q_{H}=$ heat quantity for chemical heat pump and heat pump, respectively

[kcal]

$T \quad=$ temperature

$W_{G}, W_{H}=$ work required for chemical heat pump and heat pump, respectively

[kcal]

$\eta_{O}, \eta_{H}=$ thermal efficiency for chemical heat pump and heat pump, respectively

$\eta_{e H}, \eta_{Q W}=$ practical efficiency for heat pump and heat engine, respectively

$\eta_{Q C}, \eta_{W C}=$ coefficients of performance for chemical heat pump defined by Eq. (2)

\section{Literature Cited}

1) Fujii, S., H. Kameyama, K. Yoshida and D. Kunii: $J$. Chem. Eng. Japan, 10, 224 (1977).

2) Kast, W.: Chem. Ing. Tech., 48, 205 (1976).

3) Sega, K.: "Review on Energy Saving Technologies", p. 222, Fuji-Technosystem Co. (1975). 